\title{
Comentarios a la contribución parafiscal cultural de los espectáculos públicos de las artes escénicas
}

\author{
Paola Andrea Gómez García*
}

Sumario. I. Introducción. II. Antecedentes normativos de la contribución parafiscal creada en la Ley 1493 de 2011. 1. Constitución Política. 2. Ley General de Cultura Ley 397 de 1997. 3. Exposición de motivos Ley de Espectáculos Públicos. III. Las contribuciones parafiscales. IV. Conclusiones. Referencias.

\section{Resumen}

El presente artículo realiza un estudio acerca de la naturaleza jurídica de la Contribución parafiscal de los espectáculos públicos de las artes escénicas, creada por el Congreso colombiano a través de la Ley 1493 de 2011. Haciendo un repaso por las características generales de las contribuciones parafiscales y contrastando estas con las propias de la contribución creada para las artes; la autora pretende demostrar que la naturaleza jurídica de dicho tributo, responde más a otra categoría impositiva, que a una contribución parafiscal propiamente dicha.

\section{Introducción}

Con la Constitución de 1991, surge para el Estado el deber de promover y fomentar el acceso a la cultura para todos los colombianos en igualdad de oportunidades (Constitución Política de Colombia, artículo 70). En desarrollo de tal mandato, el Gobierno Nacional, a través de los lineamientos de Política Cultural, da un énfasis especial al lugar que los espectáculos públicos de las artes escénicas ocupan en la cultura colombiana, identificándose a partir de esto la necesidad de contar con infraestructura cultural adecuada para esta categoría de espectáculos, ya sea a través de la construcción de escenarios o a través de la adecuación de los ya existentes.

En cumplimiento de tal mandato, y luego de la presentación del proyecto de ley que regularía la materia en marzo de 2009, se expide finalmente el 26 de diciembre de 2011 la Ley 1493, "por la cual se toman medidas para formalizar el sector del espectáculo

* Estudiante de Maestría en Gobierno y Políticas Publicas, de la Universidad Externado de Colombia, en convenio con la Universidad de Columbia, de Nueva York; Especialista en Derecho Aduanero y abogada de la Universidad Externado de Colombia; Docente investigadora de la Universidad Externado de Colombia, Bogotá, Colombia. correo-e: paola.gomez@uexternado.edu. co. Para citar el artículo: Gómez, P.A. (2016). "Comentarios a la contribución parafíscal cultural de los espectáculos públicos de las artes escénicas". Revista de Derecho Fiscal n. ${ }^{\circ}$, Bogotá: Universidad Externado de Colombia.pp. 59-66. DOI: http://dx.doi.org/10.18601/16926722.n8.05 
público de las artes escénicas, se otorgan competencias de inspección, vigilancia y control sobre sociedades de gestión colectiva y se dictan otras disposiciones".

En el marco de los principios consagrados en la Ley 1493 de 2011, se adoptan medidas encaminadas a proteger al sector de artistas y productores de las artes escénicas, promover la eliminación de trámites dispendiosos a los empresarios que realizan este tipo de eventos, y se dan lineamientos para el adecuado funcionamiento de las Sociedades de Gestión Colectiva, entre otros aspectos. De las modificaciones insertas en la nueva Ley, cabe señalar que, en cuanto al fortalecimiento del sector, las medidas de orden tributario que se adoptaron en aras de conseguir recursos para el sector han sido las más importantes al dar evidencia (en sus 5 años de implementación) de los cambios que la consecución de recursos para los escenarios culturales han traído para el país.

Dentro de la gama de alicientes tributarios con que cuenta la Ley 1493, se precisa que la creación de la contribución parafiscal de los espectáculos públicos de las artes escénicas (en adelante EPAE) busca gravar todas las boletas o derechos de asistencia a espectáculos que superen las 3 Unidades de Valor Tributario, con un $10 \%$ sobre el valor total de la boleta. Aunado a tal disposición, es objeto de la Ley la disminución de la retención en la fuente para artistas extranjeros que presten sus servicios artísticos en Colombia, pasando de una tarifa del $33 \%$ al $8 \%$.

En cuanto a la prestación de servicios artísticos conexos con el despliegue de la labor artística de los EPAE, la Ley excluye del IVA a todos los servicios conexos a la actividad principal: montaje de los escenarios para el espectáculo, elaboración del vestuario, creación de escenarios y servicios de com- posición musical, entre otros. Finalmente, y no por ser menos importante, se establece en el cuerpo normativo la deducción de hasta un $100 \%$ en el impuesto sobre la renta para quienes inviertan en la construcción, reforzamiento o adecuación de escenarios destinados exclusivamente a la presentación de espectáculos públicos de las artes escénicas.

El entramado de medidas del orden tributario resultan sumamente atractivas, al no solo encaminar la consecución de recursos a un fin específico, sino que, además, esto va de la mano con la promoción del país como destino de grandes eventos y, a su vez, la formalización del sector del espectáculo público en el país. Si bien la Ley 1493 de 2011 derogó los impuestos que existían anteriormente sobre los espectáculos públicos, estableciendo en su lugar la contribución parafiscal cultural, debe precisarse que i) el Impuesto Nacional a Espectáculos Públicos de que trata el numeral 1 del artículo 7 de la Ley 12 de 1932 y el literal a) del artículo 3 de la Ley 33 del 68; ii) el Impuesto con destinación al Deporte de que trata el artículo 77 de la Ley 1818 de 1995, y iii) el impuesto al fondo de pobres autorizado por Acuerdo 399 de 2009 para el Distrito de Bogotá, se mantienen para todos los demás espectáculos no considerados de las "artes escénicas". La Ley define a los espectáculos públicos de las artes escénicas como las representaciones en vivo de expresiones artísticas en teatro, danza, música, circo sin animales, magia y todas sus posibles prácticas derivadas o creadas a partir de la imaginación, sensibilidad y conocimiento del ser humano, que congregan a la gente por fuera del ámbito doméstico (Ley 1493 de 2011, artículo 3).

Precisado el concepto anterior y contando con un marco normativo encargado de regular el componente financiero para esta activi- 
dad cultural, el esquema de la contribución parafiscal tiene como hecho generador la venta o entrega de boletería -cualquiera que sea su forma de pago- que tenga un precio igual o superior a 3 UVT (Concepto Ministerio de Cultura 001 de 2012). Para la determinación de la base gravable, no resulta del todo claro a qué se refiere el ente rector de las artes en Colombia cuando integra dentro de los rubros a tener en cuenta para la determinación de la base gravable de la contribución los "aportes en especie, compensaciones de servicios, cruces de cuentas", o cualquier otra forma que financie la realización del EPAE (Concepto Ministerio de Cultura 001 de 2012). Tal indeterminación sobre los verdaderos montos que se deben tener en cuenta al momento de calcular la base gravable ha llevado a que, en la práctica, el Ministerio de Cultura como recaudador de la contribución solo lo haga sobre el valor neto de la boletería (sin incluir el valor del servicio de venta y el del impuesto al consumo cuando haya lugar), dejando, por demás, lo contenido en el numeral 1 del Concepto 001 de 2012 como un simple saludo a la bandera.

En cuanto a la forma de pago y recaudo de la contribución, el mismo Concepto 001 de 2012 sugiere como responsables de la declaración y pago del tributo a los productores -permanentes y ocasionales- de espectáculos públicos. Si bien la presentación y pago corresponden a estos sujetos, la Ley prevé como "responsables solidarios" para el pago de la contribución a los artistas, intérpretes o ejecutantes de las obras y a quienes perciban beneficios económicos del EPAE (Ley 1493 de 2011 artículo 9 par. 1). Si bien la determinación de los responsables es clara, no sobra mencionar que los pagos que realizan los productores al presentar su declaración se hacen con el dinero que cada consumi- dor final o espectador paga cuando compra la boleta. Hay una clara división entre el responsable y obligado, y entre "quienes conforman el sector de las artes escénicas" y quienes no.

Aunado a este aspecto, la Ley asigna la responsabilidad de retener los recursos de la contribución a los operadores de boletería en línea; estas personas jurídicas son los encargados directos de realizar la operación de venta de boletas y, en consecuencia, los responsables de presentar la declaración de retención de la contribución parafiscal de los EPAE. Al igual que las declaraciones de retención en la fuente, estas se presentan cada mes.

Respecto de las competencias otorgadas a las Entidades Territoriales, la norma determinó que, en cumplimiento del principio de autonomía territorial consagrado en la Constitución Política (artículo 287), las decisiones referentes a la destinación y manejo de la contribución parafiscal cultural de los espectáculos públicos de las artes escénicas, si bien son recursos recaudados por el Ministerio de Cultura y ejecutados según los lineamientos establecidos por esta entidad, su destinación e inversión se encuentra a cargo de las entidades territoriales, que por medio de Acuerdos, Decretos u Ordenanzas deberán implementar las medidas necesarias tendientes a garantizar el correcto aprovechamiento del tributo.

El camino a seguir desde la presentación y pago de la contribución parafiscal por parte de los responsables señala que, una vez recaudado el dinero por el Ministerio de Cultura, este es girado (mes vencido) a los municipios o distritos en donde se haya llevado a cabo el espectáculo público. Los dineros son consignados en una cuenta especial que previamente ha abierto la Secretaría 
de Hacienda del lugar o la entidad que haga sus veces, y en la cual no se podrán recibir recaudos por otros conceptos ni afectarse para otras finalidades.

De forma concomitante a la entrega de recursos a la Secretaría de Hacienda, es labor de la Secretaría de Cultura del mismo municipio o distrito establecer los lineamientos para la inversión del dinero. ¿En qué invertir lo recaudado? Los procesos de selección para la inversión de los recursos a cargo de las entidades territoriales siempre deben ceñirse a las directrices establecidas en el Decreto 1240 de 2013 (artículos 2 y 3). Estos recursos están exclusivamente orientados a la inversión en construcción, adecuación, mejoramiento y dotación de infraestructura de los escenarios para la presentación de espectáculos públicos de las artes escénicas, y para compra de infraestructura ya existente (Gutiérrez González, Alfonso; Abaunza Galvis y Godoy, 2015, pág. 51).

El monto de ejecución por vigencia fiscal es definido a través de las convocatorias que, para la asignación de los mismos, abre cada año la Secretaría de Cultura de los municipios beneficiados con los dineros del tributo. Del total del dinero recaudado, debe asignarse un porcentaje a escenarios privados o mixtos, y otro para los de naturaleza pública.

Hasta este punto hemos visto cómo la propuesta tributaria consagrada en la Ley 1493 de 2011 se orienta a aliviar las cargas impositivas y a que los recursos generados en razón de la contribución parafiscal cultural regresen al sector de espectáculos públicos a través de una figura que permite reasignar los mismos entre los propios agentes sin importar su naturaleza pública, privada o mixta.

Fue intención del legislador que los recursos obtenidos por el pago de la contribución cultural de los espectáculos públicos de las artes escénicas, creada por el artículo 7 de la Ley 1493, tuviera la tipología tributaria de una contribución parafiscal, al considerar que su recaudo proviene de las arcas de un sector, para que luego del proceso de asignación que se estudió hace unas líneas, estos recursos se reintegraran en beneficios para ese mismo sector.

\section{Antecedentes normativos de la contribución parafiscal creada en la Ley 1493 de 2011}

\section{Constitución Política}

La Constitución Política de 1991 ha sido la gran precursora del fomento a las artes y la cultura en el país al proclamar a Colombia como un Estado Social de Derecho. Si bien directamente no toca el tema de los espectáculos públicos como representaciones artísticas, en varios de sus artículos encontramos referencias a la cultura y el deber del Estado de promover y fomentar el acceso a la misma (Constitución Política, artículo 70) y el reconocimiento a la expresión libre de las tradiciones y manifestaciones culturales como expresión de la nacionalidad (Constitución Política, artículo 71).

\section{Ley General de Cultura - Ley 397 de 1997}

Con la expedición de la nueva Carta Política, la idea de concebir un compendio de normas culturales tomó la fuerza necesaria para decantar en la Ley 397 de 1997 - Ley General de Cultura. A partir de 1993, las dispersas disposiciones normativas encargadas de regular temas culturales fueron producto de debates y reorganizaciones que dieron lugar a un cuerpo general de normas para 
la cultura. En palabras de Ramiro Osorio (director de Colcultura), era imperioso dar un desarrollo adecuado a los principios de la Constitución de 1991, a las exigencias de estimular la iniciativa individual y comunitaria y contribuir a la modernización del Estado (Osorio en Sáenz Vargas, 1993).

Con la promulgación de la Ley General de Cultura, la visibilización de los espectáculos públicos como manifestación artística, encontró un fuerte asidero al consagrarse como uno de los principios fundamentales de la Ley el garantizar el acceso a la cultura a todos los colombianos, a través del fomento a la creación, ampliación y adecuación de infraestructura cultural (Ley 397 de 1997 artículo 1 numeral 11).

Con una clara disposición de orden legal, el Estado sería ahora el encargado de propender al cumplimiento de los lineamientos establecidos en la Ley. Para la concreción de tal deber, durante el gobierno de Álvaro Uribe Vélez, la Ministra de Cultura de turno, con el apoyo del congresista Simón Gaviria, presenta en 2009 el proyecto de ley que años más tarde se materializaría en la promulgación de la Ley de Espectáculos Públicos.

\section{Exposición de motivos Ley de Espectáculos Públicos}

Es importante señalar que la industria del espectáculo público en artes escénicas, al convocar manifestaciones artísticas como el teatro, la danza, la música o el circo sin animales, se relaciona con organizaciones mundiales de la industria cultural, hoy apenas incipientes en el país. Dentro de los mínimos que un Estado social de derecho debe garantizar a sus ciudadanos, está el velar por el acceso y cumplimiento de los derechos sociales, económicos y culturales. Antes de la expedición de la Ley 397 de 1997, el sector de espectáculos era un asunto rezagado en el país, al no considerar a Colombia como un país atractivo para este tipo de propuestas artísticas. Un adecuado equilibrio entre el papel regulador y compensador del Estado, el fomento a la actividad cultural y el uso de incentivos fiscales eficientes que apoyen a la industria cultural y promuevan la sostenibilidad y la innovación fueron los argumentos centrales que impulsaron la expedición de una Ley especial para el desarrollo artístico del país en este campo.

\section{Las contribuciones parafiscales}

Partiendo de la premisa de que la Constitución misma no distingue claramente las categorías tributarias al asumir como iguales los tributos y las contribuciones entre otras categorías, vemos cómo el panorama para determinar qué se entiende por "contribuciones parafiscales" no ha sido un tema zanjado a cabalidad en nuestro ordenamiento jurídico.

De un lado, el Decreto 111 de 1996, por el cual se conforma el Estatuto Orgánico del Presupuesto, dispone en el artículo 29 que son contribuciones parafiscales los gravámenes establecidos con carácter obligatorio por la ley, que afectan a un determinado y único grupo social y económico y se utilizan para beneficio del propio sector. El manejo, administración y ejecución de estos recursos se hará exclusivamente en la forma dispuesta en la ley y se destinarán sólo al objeto previsto en ella, al igual que los rendimientos y excedentes financieros que resulten al cierre del ejercicio contable. El mismo artículo señala que las contribuciones parafiscales administradas por los órganos que formen parte del presupuesto general de la Nación se incorporarán al presupuesto solamente 
para registrar la estimación de la cuantía y en capítulo separado de las rentas fiscales y su recaudo será efectuado por los órganos encargados de su administración.

Partiendo de las características que integran el concepto de "contribución parafiscal", encontramos que la contenida en la Ley 1493 de 2011 carece del elemento que las establece como "un gravamen que afecta a un único y determinado sector socio-económico, para luego beneficiar al mismo" (Decreto 111 de 1996 artículo 29). La necesidad de contar con esta distinción al hablar de contribuciones parafiscales ha sido repetida en varios fallos de la Corte Constitucional, así:

La Corte considera que el actor parte de un supuesto equivocado, en la medida en que confunde las contribuciones parafiscales con auxilios o donaciones de los prohibidos por el artículo 355 de la Constitución Política.... La administración y recaudo de recursos parafiscales en nada se relacionan con la prohibición de otorgar auxilios y donaciones contenida en el artículo 355 de la Carta, prohibición que por lo demás, como lo ha sostenido la jurisprudencia, se refiere exclusivamente a negocios jurídicos que tengan una causa "donandi" y no a otros que carezcan de ella, como es el caso de las contribuciones parafiscales agropecuarias y pesqueras, en las cuales se busca que su administración y recaudo genere productividad en beneficio de la misma colectividad, pues esas contribuciones gravan a un sector de la sociedad para que la entidad que las administre efectúe inversiones y brinde servicios a ese mismo sector, lo que a su vez redunda en beneficio general (Sentencia C-651 de 2001).

Es claro cómo del aparte citado se reafirma que el "beneficio" debe redundar en el mismo sector que ha reunido o recaudado el dinero a título de contribución parafiscal. Tal elemento no resulta del todo claro en el caso de la contribución por espectáculos, ya que se sabe que el dinero que se recauda por concepto de contribución parafiscal proviene de los particulares, quienes en su calidad de espectadores asumen el tributo por cada boleta que compran para asistir a un espectáculo público. Mal se haría en asumir -como lo ha hecho el Ministerio de Cultura-, que los espectadores "hacen parte del sector de espectáculos", siendo tal situación un desfase de la realidad.

Si bien la creación de tributos a las actividades culturales se justifica en gran medida, es por vía excepcional que la Constitución Política autoriza al Estado a conceder subvenciones o estímulos económicos a particulares sobre aquellas actividades "dignas de apoyo", básicamente por su contenido social y por la utilidad que brindan a los ciudadanos. En este sentido, señala la Sentencia C-152 de 1999 sobre los beneficios a la cultura:

El Estado creará incentivos para personas e instituciones que desarrollen y fomenten la ciencia y la tecnología y las demás manifestaciones culturales y ofrecerá estímulos especiales a personas e instituciones que ejerzan estas actividades". En este orden de ideas, los incentivos económicos que eventualmente ordene la ley con fundamento en el artículo 71 de la C.P., constituyen una excepción válida a la prohibición contenida en el artículo 355 de la Carta.

La Constitución, aparte de permitir la concesión de incentivos o estímulos a las personas dedicadas a la creación o al desarrollo cultural, no determina la forma concreta que estos podrían revestir. Corresponde al Le- 
gislador, en el contexto de las políticas que en este campo considere conveniente dictar, definir el contorno y alcance concretos de los beneficios que en un momento dado pueden servir como instrumentos de desarrollo científico, tecnológico y cultural.

Para el caso de la creación de la contribución parafiscal de los EPAE en cumplimiento del deber del Estado de "fomentar la cultura", consideramos que la tipología elegida para la consecución de recursos no resulta la más adecuada al carecer aquellos de algunos elementos estructurales del concepto de contribución parafiscal. Tal desacierto no solo se convierte en una problemática terminológica, sino que su inclusión estimativa dentro del Presupuesto General de la Nación resulta una clara afrenta a la autonomía de las entidades territoriales.

\section{Conclusiones}

Estudiados los aspectos más destacados de la naturaleza de las contribuciones parafiscales, encontramos que la figura jurídica creada a través de la Ley 1493 de 2011 no responde a cabalidad a una "contribución parafiscal", al no beneficiar directamente al sector encargado de poner el mayor porcentaje de recursos en razón al recaudo de dicho tributo.
Así mismo, en un intento desesperado por promover la construcción de infraestructura cultural -fin primigenio de la Ley 1493-, se violentó de manera abrupta el principio de autonomía presupuestal de las entidades territoriales (Sentencia C-478 de 1992), al encontrarse en la actualidad supeditadas al recaudo y administración de los recursos de la contribución por parte del sector central en cabeza del Ministerio de Cultura.

Si bien la intención del legislador fue dar la categoría de "contribución parafiscal" al citado tributo en aras de incentivar y reactivar el sector de las artes escénicas, por demás abandonado en Colombia, en estricto sentido, los elementos materiales de la citada contribución responden y se acercan más a las características de un impuesto con destinación específica. Así las cosas, se estaría en presencia de una denominación errada $-\mathrm{y}$ en consecuencia de ello- la asignación de los recaudos por contribución cultural no se correspondería con los mandatos de la Constitución Política en materia de configuración legislativa, ni a los principios del derecho presupuestario ni al principio de autonomía de las entidades territoriales consagrado en la Constitución Política.

\section{Referencias}

\section{Bibliográficas}

Asorey, R. O., Amatucci, A., \& Vega, M. A. P. (2008). La autonomía del derecho de la hacienda pública y el derecho tributario: reflexiones sobre su autonomía. Bogotá: Universidad del Rosario.

Gutiérrez González, Y.; Alfonso, S. M.; Abaunza Galvis, S., \& Godoy Córdoba, T. (2015). La contribución parafiscal del espectáculo público en Bogotá: un balance positivo.

Mauricio, P. V. (2006). Derecho de la hacienda pública y derecho tributario. Las ideas políticas de la hacienda pública (No. LG-0065). TEMIS SA. 
Osorio Fonseca, Ramiro (1993). "Presentación” en Documentos críticos sobre Legislación Cultural, compilación de Carlos Roberto Sáenz Vargas. Bogotá: Instituto Colombiano de Cultura COLCUlTuRA.

Romero-Molina, C. A.; Lanzziano-Rizo, C. \& García-Correa, L. M. (2012). La parafiscalidad en la Constitución Política de Colombia de 1991.

\section{Normativas}

Ley 397 de 1997.

Ley 1493 de 26 de diciembre de 2011.

Exposición de motivos de la Ley 1493 de 2011.

Decreto 111 de 1996.

\section{Jurisprudencia}

Corte Constitucional, Sentencia C-651 de 2001.

Corte Constitucional, Sentencia C-152 de 1999.

Corte Constitucional, Sentencia C-478 de 1992. 